\title{
Precise altimetric topography in ice-sheet flow studies
}

\author{
F. REMY AND J. F. MINSTER \\ UMR 39/GRGS 18, av. E. Belin, Toulouse Cedex 31055, France
}

\begin{abstract}
The precision of radar altimetry above an ice sheet can improve glaciological studies such as mass balance surveys or ice-sheet flow models, the first by comparing altimetric data at different times (see this issue), the second by testing or constraining models with data. This paper is a first step towards the latter. From a precise topography deduced by inversion of altimetric data (Remy and others, 1989), we calculate ice-flow direction, balance velocity and basal shear stress. The rheological parameters involved in the relation linking velocity, stress and temperature are then derived by least-squares regression. Ice flow is well represented by setting the Glen parameter, $n$ to $1 \pm 0.25$ and the activation energy as $70 \pm 10 \mathrm{~kJ} \mathrm{~mol}^{-1}$.
\end{abstract}

\section{INTRODUCTION}

Relations describing the mechanical response of ice to an applied stress are fundamental for understanding icesheet dynamics. The commonly used relation is the Vialov (1958) differential equation, which links the derivative of the ice-deformation velocity with respect to depth in the ice sheet to the effective stress $\tau$ at power $n$, where $n$ is called the Glen parameter, and to the ice temperature via an Arrhenius-type relation depending on an activation energy $Q$ (i.e. of the type $B(T)=$ $\left.B_{0} \exp (-Q / R T)\right)$. Although the relation is well-supported by experiments or in situ measurements, a very large set of empirical values is found in the literature: values of the Glen parameter vary from 1 to 4.5 , with a mean value of 3 (Paterson, 1981). Homer and Glen (1978) reviewed 23 values of activation energy between 40 and $135 \mathrm{~kJ} \mathrm{~mol}^{-1}$, and found a new value of $75 \mathrm{~kJ}$ $\mathrm{mol}^{-1}$.

Concerning the Glen parameter, a quasi-Newtonian viscosity $(n \approx 1)$ is suggested for polar ice as long as grain growth occurs (Pimienta and Duval, 1987). This creep concerns the first hundreds of $m$ at the top of the ice sheets. A power law creep with $n=3$ is expected when continuous recrystallization occurs; it is named tertiary creep. Results concerning the intermediate ice layers are uncertain: rotation recrystallization involving sub-grainrotation and grain-boundary migration was suggested by Pimienta and Duval (189) for these kinds of ice. Several interpretations of field data suggest a flow with $n=3$ (Paterson, 1983; Reeh and others, 1985) whereas others have given $n$ from 1 to 2 (Lliboutry and Duval, 1985; Pimienta and Duval, 1987). Moreover, the exact boundary between different types of creep and their relative importance is not very well known. Creep associated with rotation recrystallization probably occurs for $80 \%$ of the ice sheets but its exact importance is difficult to evaluate. In particular we do not know whether it is significant in the deformation processes which occur mostly at the bottom.

Activation energy seems to depend on temperature. Creep tests made by Duval and Le Gac (1982) gave a value of $78 \pm 4 \mathrm{~kJ} \mathrm{~mol}^{-1}$ for temperatures between -10 and $-25^{\circ} \mathrm{C}$. A larger value is expected for warmer temperatures. Finally, the pre-exponential factor $\left(B_{0}\right)$ depends on crystal structure, on concentrations of impurity and other factors (Budd and Jacka, 1989).

Laboratory measurements of these parameters can be done easily only for high stress, because of the time needed to achieve measurable deformation. They thus usually yield large values of $n$ (Lliboutry and Duval, 1985), in contrast to borehole studies which indicate a Newtonian flow.

Empirical studies from estimations of flow velocity and stress are a means to get information over a wide range of stress, strain rate or temperature. The major difficulty lies probably in the stress computation which requires a precise ice-sheet surface topography. This was attempted by Young and others (1989) and Hamley and others (1985) using the topography of Zwally and others (1983) and of Drewry (1983). Neither of these studies took into account the temperature dependence; both found a high value of $n$ for the whole data set.

This paper re-estimates parameters of the constitutive flow law from the same empirical approach, using a very precise topography deduced by inversion of satellite altimeter data (Remy and others, 1989). We focus on the area between 1500 and $3000 \mathrm{~m}$, where the topography is very precise. In addition, temperature dependence is taken into account. The first section of the paper is devoted to formulating the constitutive law: the formulation must be complete enough to be realistic and simple enough to allow regression. Then the stress, $U / H$ (ratio between mean balance velocity and thickness) and temperature are computed along ice flowlines derived from surface topography, to determine flow parameters. 
Finally, rheological parameters $n$ and $Q$ are derived by least-squares regression and by assuming that, locally, they do not vary along a flowline. This semi-empirical approach is applied to four sectors of Antarctica (Fig. 1).

\section{CONSTITUTIVE EQUATION}

In this section we write the constitutive equation linking the velocity at a given position $x$, along a flowline, to other ice-sheet parameters. The whole presentation is based on steady-state hypothesis.

In cold ice sheets, temperature and velocity are closely related through the Vialov (1958) differential equation which links the derivative of the "deformation velocity" $u(z)$ with respect to height above ice bottom $z$, to temperature $T$ and basal shear stress $\tau$ :

$$
\mathrm{d} u(z) / \mathrm{d} z=2 B_{0} \exp \left(Q / R T_{\mathrm{m}}-Q / R T(z)\right)(1-z / H)^{n} \tau^{n}
$$

where $H$ is the ice thickness and $R$ is the gas constant. $T_{\mathrm{m}}$ is the melting temperature at the bottom of the ice sheet $\left(T_{\mathrm{m}}=273-H / 1503\right.$, where $T_{\mathrm{m}}$ is expressed in $\left.\mathrm{K}\right)$. The stress is taken as:

$$
\tau=\rho g H \propto
$$

where $\rho$ is the ice density, $g$ is the acceleration of gravity and $\propto$ is the surface slope along a flowline direction. We neglect other stress components. First, the stress is calculated over a distance of the order of $50 \mathrm{~km}$ : the effect of longitudinal stress and stresses due to the irregular bedrock topography are then smoothed (Young and others, 1989). Secondly, we avoid domes and coastal regions where shear stress is probably not dominant. To integrate Equation (1), we choose the formulation of Lliboutry (1979). He noted that maximum deformation occurs in the first $100 \mathrm{~m}$ above the bottom where temperature varies linearly with depth, and that the integration depends only on the bottom temperature gradient. He deduced the velocity profile as:

$$
u(z)=\psi(z, H) U
$$

where

$$
\psi(z, H)=[(p+2) /(p+1)]\left(1-(1-z / H)^{(p+1)}\right)
$$

and $U$ is the averaged velocity over the ice column such that

$$
U / H=\left[2 B_{0} /(p+2)\right] \tau^{n} \exp \left(k\left(T_{\mathrm{b}}-T_{\mathrm{m}}\right)\right)
$$

with

$$
k=Q /\left(R T_{\mathrm{b}}^{2}\right)
$$

and

$$
p=n-1+k G_{0} H .
$$

$T_{\mathrm{b}}$ is the mean bottom temperature averaged over the first $5 \%$ of the bottom ice (which corresponds to about the first $100 \mathrm{~m}$ ) and $G_{0}$ is the bottom temperature gradient, taken as $0.022^{\circ} \mathrm{C} \mathrm{m}^{-1}$ corresponding to $\Phi=50 \mathrm{~mW} \mathrm{~m}^{2}$. Note that $(p+2)$ arises in Equation (5), which is linked not only to the flow parameters $n$ and $k$ but also to the ice thickness $H$. The pre-exponential factor $B_{0}$ is independent of the ice-column characteristics.

\section{COMPUTATIONAL SGHEME AND "FLOW PARA- METERS"}

Assuming that they are constant, $n, k$ (or equivalently $Q$ ) and $B_{0}$ can be estimated by regression from Equation (5) if $U / H$, the basal shear stress $\tau$ and the bottom temperature $T_{\mathrm{b}}$ are known along a set of geographical positions. An iterative scheme will be used. First, ice flowlines are deduced from the direction of maximum surface slope of the ice topography (Fig. 1). Between two flowlines, the steady-state continuity equation is applied step by step:

$$
\begin{aligned}
& U(x+\mathrm{d} x) H(x+\mathrm{d} x) l(x+\mathrm{d} x)= \\
& U(x) H(x) l(x)+\bar{b}(x) \bar{l}(x) \mathrm{d} x
\end{aligned}
$$

where $x$ is the flow direction of the ice divide to the coast and $\mathrm{d} x$ is the step, chosen as $20 \mathrm{~km}$, the overbar designing mean value between $x$ and $x+\mathrm{d} x \cdot l(x)$ is the distance between two flowlines. Ice thickness $H(x)$ is derived from Drewry (1983), the surface ice-sheet topography from Remy and others (1989) and accumulation rate $b(x)$ from Radok and others (1987). $U(x)$ and $U / H$ can then be computed step by step.

The flowlines are derived from the surface slope of the topography: the initial distance $l(x)$ is $20 \mathrm{~km}$. The

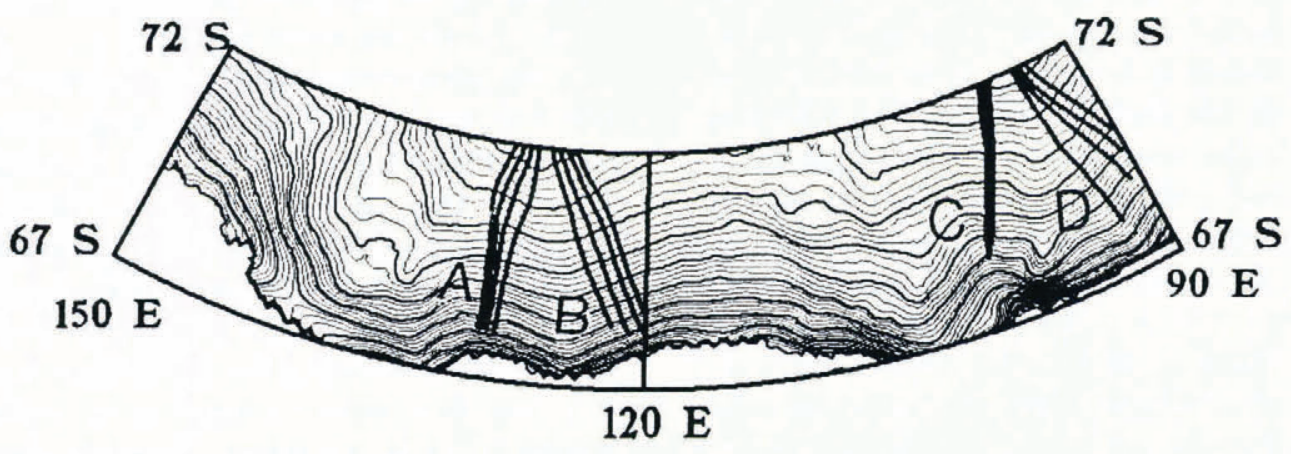

Fig. 1. Topographic map of the selected sector of Antarctica, deduced from Seasat data, as explained in Remy and others (1989). Bold isolines are each $100 \mathrm{~m}$. The figure shows also the four selected flowlines. 
integration starts from the divide line, using the topography of Drewry (1983). North of $72^{\circ} \mathrm{S}$, our altimetric topography is used, and only the results corresponding to the latter are discussed. Surface slope $\propto$ is deduced from the topography by fitting a biquadratic form over $25 \mathrm{~km}$ around each point; stress is then deduced from Equation (2). The calculation is stopped at $68^{\circ} \mathrm{S}$ because the quality of the altimetric topography is seriously degraded north of this line.

The bottom temperature must be estimated from the thermodynamic equation (Lliboutry, 19877) which, in the steady-state hypothesis, reads

$$
\begin{aligned}
\kappa \partial^{2} T / \partial z^{2} & -u \partial T / \partial x-w \partial T / \partial z \\
& +\tau(1-z / H) / \rho C \partial u / \partial z=0
\end{aligned}
$$

where $\kappa$ is the thermal diffusivity, $C$ the specific heat capacity and $w$ the vertical velocity. In this equation, we consider vertical diffusion (first term), horizontal advection (second term), vertical advection (third term) and dissipation (last term). $w$ is calculated from mass continuity:

$$
\partial w / \partial z+\partial u / \partial x+\partial v / \partial y=0
$$

In Equations (9) and (10) $u(z)$ is estimated as in Equation (3), from $U$ computed at the same place by Equation (8). This has been proven a sufficient approximation to estimate bottom temperature (Ritz, 1987).

The boundary conditions are, at the base of the ice sheet, the bottom temperature gradient $\left(G_{0}\right)$, and at the surface the temperature $T_{\mathrm{s}}$ is derived from Radok and others (1987). $\partial T / \partial x$ at the surface is supposed to be equal to $\alpha \lambda$ where $\lambda$ is the atmospheric vertical temperature gradient, assumed to be $0.0115 \mathrm{deg} \mathrm{m}^{-1}$ in the selected region (Huybrechts and Oerlemans, 1988). The initial conditon is $u(z)=0$ at the dome, corresponding to a purely vertical flow induced by accumulation at the surface.

Along each flowline, we then compute $U / H, \tau$ and $T_{\mathrm{b}}$ from Equations (5), (8), (2), (9) and (10). Because $u(z)$ depends on $p$ and $k, T_{\mathrm{b}}$ is calculated first by using initial values for these parameters $(n=3, k=0.1$; Radok and others, 1987). The whole process (i.e. calculation of $U / H, \tau$ and $T_{\mathrm{b}}$ up to re-estimation of $n$ and $k$ as discussed below) is then itereated with the new couple of values. It converges in two iterations and the results were shown to be unsensitive to the choice of the initial values. The calculations have been achieved along four different flowlines (Fig. 1). The values of the involved parameters along flowline B are illustrated in Figure 2.

\section{RHEOLOGICAL PARAMETERS}

In this section, we analyze the best-fit values for the activation energy $Q$ (via $k$, Equation (6)), $n$, and the preexponential factor $B_{0}$. We only consider data where $T_{\mathrm{b}}$ is less than $-10^{\circ} \mathrm{C}$. Thus we exclude areas where melting and strong basal sliding might occur. Figure 3 shows $U / H$ versus stress for the four flowlines: the link between these parameters is not linear even in a logarithmic scale. Moreover, for flowlines A or D, one observes an increase of the velocity when stress remains constant. A line corresponding to $n=3$ is shown for reference: as a matter of fact, if one does not take into account the temperature dependence $(k=0)$, one finds $n$ between 2.7 and 3.3 for the four flowlines. This is in good agreement with the
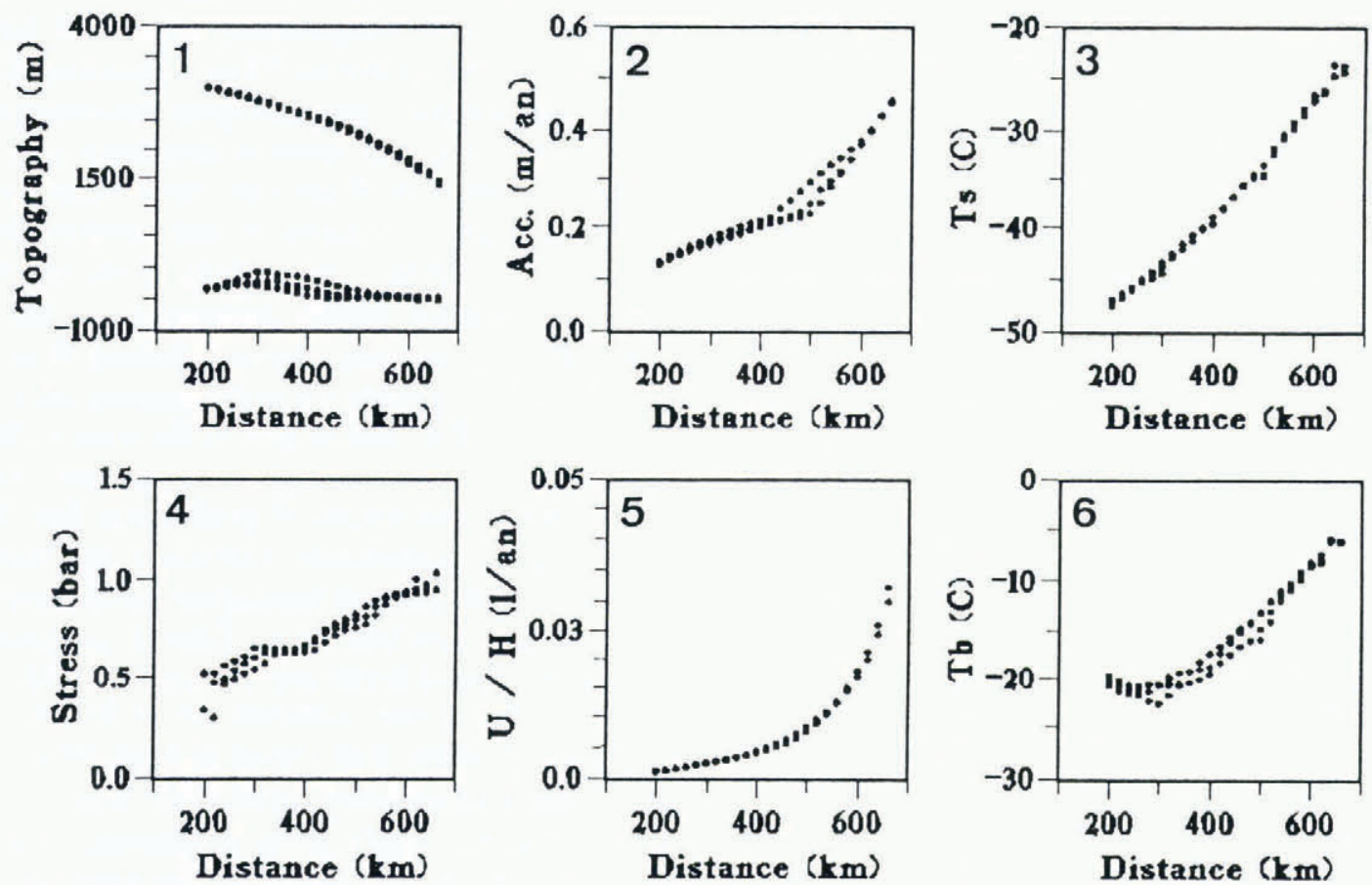

Fig. 2. Values of bedrock and surface topography (1), accumulation rate (2), surface temperature (3), stress (4), U/H

(5) and mean bottom temperature over the bottom $5 \%$ of the ice layer (6), along flowline B (Fig. 1). 

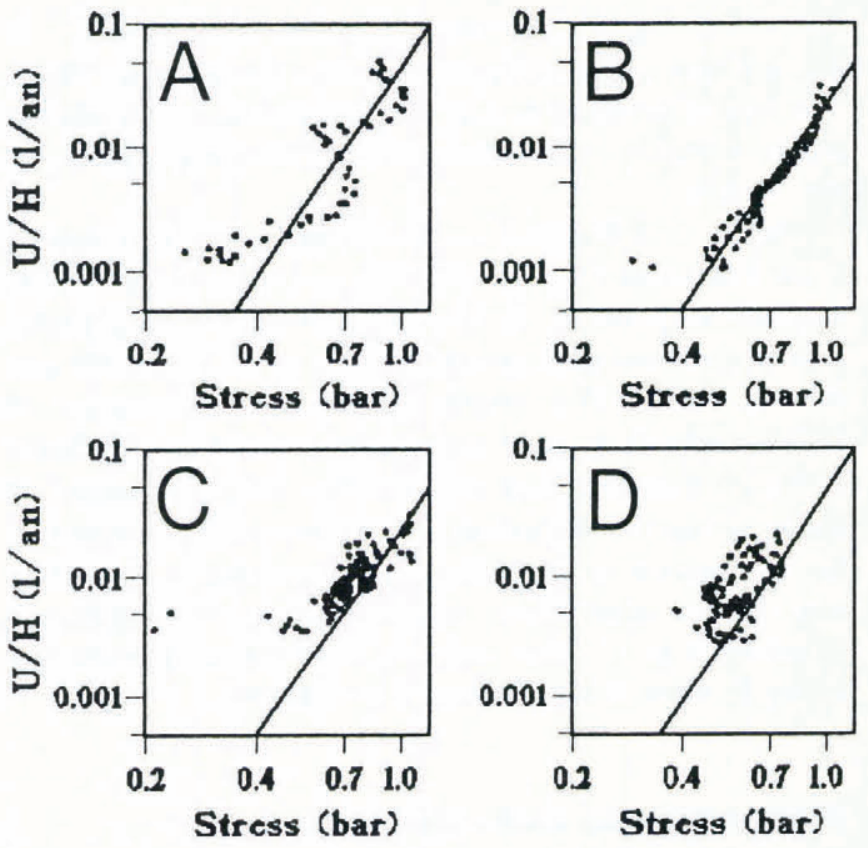

Fig. 3. $U / H$ values for four selected regions $A, B, C$ and $D$ (Fig. 1) versus stress, on a logarithmic scale. If temperature dependence is not taken into account, $n=3$ is found for the four regions. When the effect of temperature is considered, smaller values of $n$ are found (see Table 1).

Table 1. Values of the flow parameters $n, k$ and $B_{0}$ (in year ${ }^{-1} b a r^{-n}$ ) for the different flowlines of Figure 1. Various tests for flowline $B$ are also given: spatial scale used for the estimation of the surface slope (1). Estimation of vertical velocity $w$ (2), values of atmospheric lapse rate (3), geothermal flux (4-5), bedrock topography (6) and accumulation rate (7-8) are modified. Test (9) corresponds to a different surface topography (Drewry, 1983). With our topography, the Glen parameter is between 0.65 and 1.27, and $k$ between 0.8 and 0.12 , corresponding to an activation energy of $70 \pm 10 \mathrm{~kJ} \mathrm{~mol}^{-1}$

\section{Case}

Modification

$n$

$k$

$B_{0}$

\begin{tabular}{lllll}
$\mathrm{A}$ & & 1.24 & 0.120 & 0.45 \\
$\mathrm{~B}$ & 1.27 & 0.100 & 0.14 \\
$\mathrm{C}$ & 0.65 & 0.098 & 0.14 \\
$\mathrm{D}$ & 1.26 & 0.097 & 0.17 \\
& & & \\
1 & Slope on $100 \mathrm{~km}$ scale & 1.00 & 0.10 & 0.12 \\
2 & $w$ linear variations & 1.40 & 0.082 & 0.09 \\
3 & $\lambda=0.009^{\circ} \mathrm{C} \mathrm{m}^{-1}$ & 1.02 & 0.101 & 0.09 \\
4 & $\Phi=40 \mathrm{~mW} \mathrm{~m}^{-2}$ & 1.25 & 0.081 & 0.09 \\
5 & $\Phi=60 \mathrm{~mW} \mathrm{~m}^{-2}$ & 1.52 & 0.095 & 0.06 \\
6 & Bedrock $( \pm 50 \mathrm{~m})$ & 1.31 & 0.097 & 1.10 \\
7 & Accumulation $(+20 \%)$ & 1.24 & 0.095 & 0.11 \\
8 & Accumulation $(-20 \%)$ & 1.32 & 0.102 & 0.08 \\
9 & Drewry's map & 1.80 & 0.045 & 0.05 \\
& & & & \\
\hline
\end{tabular}

values of Young and others (1989) and Hamley and others (1985).

However, variations of stress and temperature change in sympathy along flowlines (Fig.2): a principal component analysis from the three-dimensional correlation matrix of these parameters (using $\log (U / H), \log \tau$ and $T_{\mathrm{b}}$ ) shows that the first eigenvalue represents more than $99.99 \%$ of the variances. As a consequence, the calculated values for $k$ and $n$ are strongly correlated.

The best-fit values for $n$ and $k$ for each flowline were derived by iterative least-squares calculation. This allows us to take into account the non-linear dependence of $p$ on $n$ and $k$ (Equation (7)). As shown in Table $1, n$ is found between 0.64 and 1.27, and $k$ between 0.10 and 0.12 , which corresponds to an activation energy between 65 and $80 \mathrm{~kJ} \mathrm{~mol}^{-1}$. This value is close to the value of $75 \mathrm{~kJ} \mathrm{~mol}^{-1}$ of Homer and Glen (1978) and of $80 \mathrm{~kJ} \mathrm{~mol}^{-1}$ of Duval and and Le Gac (1982).

The pre-exponential factor $B_{0}$ shows wide variations depending on the selected flowline. Ice-sheet dynamical models also show that $B_{0}$ is very dependent on the flowline (Huybrechts and Oerlemans, 1988). However, comparison between our result and literature values is not direct because of the normalization by $(p+2)$ (Equation (5)).

\section{CONFIDENCE TESTS}

We now discuss the different factors which may induce some errors in the derived parameters and the confidence in the above results. Because of the regular behaviour of $U / H$ and stress, in the case of flowline $\mathrm{B}$, the discussion is directed to this case first. Both ice path and accumulation rate have a cumulative effect along the flowlines, because of their contribution to the balance velocity. Their errors are propagated in all the downstream results. On the contrary, bottom temperature, stress and ice thickness only have a limited extent. Thus, a poor knowledge of the latter will introduce minimal error downstream.

In a first test, the stress is calculated over a scale of $100 \mathrm{~km}$, rather than $50 \mathrm{~km}$, only the $n$ value is diminished (Table 1, case 1). A series of tests concern the computation of $T_{\mathrm{b}}$ (Table 1, cases 2-5). First, we replace the vertical veolocity profile (advection is the dominant vertical heat-transport process) derived from Equation (10) by a linear profile, set to the accumulation rate at the top of the ice sheet and to zero at the bottom. We also test the effect of the atmospheric vertical temperature gradient $(\lambda)$ and values of geothermal flux $\Phi$. In each case bottom temperature variations are within a few degrees and the derived rheological parameters are within $20 \%$ of the nominal ones. Case 2 suggests that the approximation of Equation (3) is acceptable.

The very dense network of airborne radio-echo sounding missions near region $\mathrm{B}$ leads to a precision of the bedrock topography better than $50 \mathrm{~m}$ on the $100 \mathrm{~km}$ scale (Drewry, 1983). Even a Gaussian noise of rootmean-squares $\pm 50 \mathrm{~m}$ added on the bedrock topography leads to errors of a few per cent on the flow-parameter retrieval (Table 1 , case 6 ).

Accumulation rate is established by compilations of direct measurements on stakes and by measurements of 
trace elements in pits or ice cores: the resulting precision is probably within $20 \%$. An overestimation of the accumulation rate would lead to an overestimation of $U / H$ but an underestimated value of $T_{\mathrm{b}}$, because of the importance of vertical advection. But, as shown for cases 7-8 in Table 1 , the major effect is on $B_{0}$.

At last, we analyze the role of surface topography which is very critical because it enters into the computation of the stress (Equation (2)) and of the width and direction of flowlines (Equation (8)). The error in ice topography retrieved by satellite altimetry is due to data noise, atmospheric propagation error, orbit error and slope error. Inverse techniques allow us to take into account the whole error budget as well as the a priori covariance of the signal. This leads to the unbiased computation of a precise topography and its error map. The estimated precision for Antarctica, above $1500 \mathrm{~m}$, is about $1 \mathrm{~m}$. The resulting precision of the surface slope on a $20 \mathrm{~km}$ scale is about $10^{-4}$.

The sensitivity of the ice flowlines on the topography is very large: Equation (8) shows that the channel width $l(x)$ contributes locally and in a cumulative manner to the estimation of the parameters. An overestimation of the channel width would lead to an underestimation of the local velocity and an overestimation of the downstream velocity. We have estimated the sensitivity of the flow parameters to topography by comparing the above results with similar ones deduced from the topography of Drewry (1983). As one can see in Table 1, case 9, the dependence on the temperature $(k)$ is strongly diminished, while $n$ is enhanced. As we are confident in the metric precision of our topography, we conclude that stress and $U / H$ estimations are reliable for the first time, within the model assumptions.

From Table 1 we conclude that within the model assumptions the results of the preceding section are robust. For region $\mathrm{B}, n$ varies between 0.9 and $1.5, k$ between 0.08 and 0.1 . Between the various flowlines, the scatter is comparable: $n$ varies between 0.65 and 1.25 and $k$ between 0.1 and 0.12 , and then the activation energy $Q$ varies between 65 and $70 \mathrm{~kJ} \mathrm{~mol}^{-1}$.

\section{CONCLUSIONS}

From the very precise surface topography of the Antarctic ice sheet deduced from inversion of altimeter data, we determine ice-flow direction, balance velocity and basal shear stress. We focus on regions where bottom temperature is less than $-10^{\circ} \mathrm{C}$, and altitude between 1500 and $3000 \mathrm{~m}$. From the four selected regions we show that ice-sheet profile can be reproduced rather well by setting the Glen parameter $n$ at $1 \pm 0.25$ and the activation energy around $70 \pm 10 \mathrm{~kJ} \mathrm{~mol}^{-1}$, for a geothermal flux of $50 \mathrm{~mW} \mathrm{~m}^{-2}$, and when normal stress is neglected. If the temperature-dependent term was omitted, one would find a higher value of about 3 for $n$. A sensitivity study demonstrates that the improved precision of the surface topography is essential in this approach. When applied to the classical Drewry topography, the same calculations result in a larger value for $n(n=1.8)$ correlated with a lower value for activation energy.

\section{ACKNOWLEDGEMENTS}

We thank Dr D. Jenssen of the Meteorology Department, University of Melbourne, for the geophysical data sets. We are grateful to Dr P. Duval of the LGGE and Dr N. Young of the Australian Antarctic Division for helpful discussions and comments, and to Dr M. Monnereau for his help in the numerical resolution of the thermodynamic equation.

\section{REFERENCES}

Budd, W.F. and T.H. Jacka. 1989. A review of ice rheology for ice sheet modelling. Cold Reg. Sci. Technol., 16(2), 107-144.

Duval, P. and H. Le Gac. 1982. Mechanical behaviour of Antarctic ice. Ann. Glaciol., 3, 92-95.

Drewry, D.J. 1983. The surface of the Antarctic ice sheet. In Drewry, D., ed. Antarctica: glaciological and geophysical folio. Cambridge, Scott Polar Research Institute, Sheet 2.

Hamley, T.C., I. N. Smith and N.W. Young. 1985. Mass-balance and ice-flow-law parameters for East Antarctica. 7. Glaciol., 31(109), 334-339.

Homer, D. R. and J. W. Glen. 1978. The creep activation energies of ice. F. Glaciol., 21(85), 429-444.

Huybrechts, P. and J. Oerlemans. 1988. Evolution of the East Antarctic ice sheet: a numerical study of thermomechanical response patterns with changing climate. Ann. Glaciol., 11, 52-59.

Lliboutry, L. 1981. A critical review of analytical approximate solutions for steady state velocities and temperatures in cold ice-sheets. Z. Gletscherkd. Glazialgeol., 15(2), 1979, 135-148.

Lliboutry, L. 1987. Very slow flows of solids: basics of modeling in geodynamics and glaciology. Dordrecht, Martinus Nijhoff Publishers.

Lliboutry, L. and P. Duval. 1985. Various isotropic and anisotropic ices found in glaciers and polar ice caps and their corresponding rheologies. Annales Geophysicae, 3(2), 207-224.

Paterson, W.S.B. 1981. The physics of glaciers. Second edition. Oxford, etc., Pergamon Press.

Paterson, W.S.B. 1983. Deformation within polar ice sheets: an analysis of the Byrd Station and Camp Century borehole-tilting experiments. Cold Reg. Sci. Technol., 8(2), 165-179.

Pimienta, P. and P. Duval. 1987. Rate controlling processes in the creep of polar glacier ice. 7. Phys. (Paris), 48, Colloq. C1, 243-248. (Supplément au 3.)

Pimienta, P. and P. Duval. 1989. Rheology of polar glacier ice. (Abstract.) Ann. Glaciol., 12, 206-207.

Radok, U., D. Jenssen and B. McInnes. 1987. On the surging potential of polar ice streams. Antarctic surges - a clear and present danger? Washington, DC, U.S. Department of Energy. (DOE/ER/60197-H1.)

Reeh, N., S. J. Johnsen and D. Dahl-Jensen. 1985. Dating the Dye 3 deep ice core by flow model calculations. In Langway, C. C., Jr, H. Oeschger and W. Dansgaard, eds. Greenland ice core: geophysics, geochemistry and the environment. Washington, DC, American Geophysical Union, 56-65. (Geophysical Monograph 33.) 
Remy, F., P. Mazzeega, S. Houry, C. Brossier and J. F. Minster. 1989. Mapping of the topography of continental ice by inversion of satellite-altimeter data. 7. Glaciol., 35(119), 98-107.

Ritz, C. 1987. Time dependent boundary conditions for calculation of temperature fields in ice sheets. International Association of Hydrological Sciences Publication 170 (Symposium at Vancouver 1987 - The Physical Basis of Ice Sheet Modelling), 207-216.

Vialov, S. S. 1958. Regularities of glacial shields movement and the theory of plastic viscous flow. International Association of Scientific Hydrology Publication 47 (Sympo- sium at Chamonix 1958 - Physics of the Movement of the Ice), 266-275.

Young, N. W., I. D. Goodwin, N.W.J. Hazelton and R.J. Thwaites. 1989. Measured velocities and ice flow in Wilkes Land, Antarctica. Ann. Glaciol., 12, 192-197. Zwally, H.J., R.A. Bindschadler, A. C. Brenner, T. V. Martin and R.H. Thomas. 1983. Surface elevation contours of Greenland and Antarctic ice sheets. $\mathcal{F}$. Geophys. Res., 88(C3), 1589-1596.

The accuracy of references in the text and in this list is the responsibility of the authors, to whom queries should be addressed. 